\title{
Development of vibration shear tube method for powder flowability evaluation
}

\section{$\operatorname{AUTHOR}(\mathrm{S})$ :}

Zainuddin, M. Imran; Yasuda, Masatoshi; Liu, YiHung; Maruyama, Hiroyuki; Matsusaka, Shuji

\section{CITATION:}

Zainuddin, M. Imran ...[et al]. Development of vibration shear tube method for powder flowability evaluation. Powder Technology 2012, 217: 548-553

ISSUE DATE:

2012-02

URL:

http://hdl.handle.net/2433/152426

\section{RIGHT:}

C 2011 Elsevier B.V.; この論文は出版社版でありません。引用の際には 出版社版をご確認ご利用ください。; This is not the published version. Please cite only the published version. 


\title{
Development of vibration shear tube method for powder flowability evaluation
}

\author{
M. Imran Zainuddin ${ }^{\text {a }}$, Masatoshi Yasuda ${ }^{\mathrm{a}}$, Yi-Hung Liu ${ }^{\mathrm{b}}$, Hiroyuki Maruyama ${ }^{\mathrm{b}}$, \\ Shuji Matsusaka ${ }^{b, *}$ \\ ${ }^{a}$ IMP, 67-20 Ichibu-cho, Ikoma-shi, Nara 630-0222, Japan \\ ${ }^{b}$ Department of Chemical Engineering, Kyoto University, Kyoto 615-8510, Japan
}

\begin{abstract}
A new method for evaluating powder flowability, named vibration shear tube method has been developed. In this measurement system, the powder was discharged through a narrow gap between a vibrating tube edge and a flat bottom surface, where the particles experienced high shear forces to overcome the adhesion and friction forces. The vibration amplitude was increased during the measurement, and the mass of particles discharged was measured at constant time intervals. The amount of powder used for the measurement was about 10-40 g. The measurement time was 100-400 s. A series of experiments was carried out using alumina particles of 2-60 $\mu \mathrm{m}$ in mass median diameters. Flowability profiles, i.e. the relationships between the mass flow rate and the vibration acceleration were obtained experimentally. To characterize powder flowability, critical vibration acceleration and characteristic mass flow rate were proposed. The values of these factors were analyzed in detail and the performance of this measurement system was evaluated.
\end{abstract}

Keywords: powder flowability; measurement; vibration; shear; static/dynamic properties

* Corresponding author.

E-mail address: matsu@ cheme.kyoto-u.ac.jp (S. Matsusaka). 


\section{Introduction}

In general, the characterization of powder flowability is essential in the design and operation of powder handling processes, such as storage, discharge, transport, and packing. If the data on powder flowability are poor, problems may arise during the processes [1,2]. Much effort has been made to theoretically estimate powder flowability; however, the estimation is very difficult because there are too many factors, such as particle size, shape, density, temperature and humidity [3-5]. In addition, adhesion and agglomeration properties, or compressibility, which are related to various surface forces, static and dynamic friction, and gravity, make the analysis more complex [6-8]. Therefore, the most practical way to evaluate powder flowability is to conduct experimental tests. The important thing here is to choose appropriate methods according to actual operation. For example, angle of repose, avalanche angle, cohesiveness and compressibility are key factors for powder storage; while for powder transport, conditions to make particles flow, mass flow rate, flow stability, and hysteresis should be taken into account [9]. Furthermore, powder flowability should be evaluated under both static and dynamic states. It is inappropriate to extend the results obtained from a static evaluation method to a dynamic process and also from a dynamic evaluation method to a static process [10].

In the past decades, various evaluation methods have been developed, e.g. Carr's method [11], Jenike shear tester [12], and Hall flowmeter [13]. However, these methods have disadvantages. Some of them are difficult to operate $[14,15]$ and are not suitable to evaluate flowability in various states. To counter these problems, an indentation method [16], a vibratory feeder method [17], an avalanche method [18] and a twisted blade method [19] were proposed. In addition, a method using a vibrating 
capillary was also proposed $[9,20]$. This method is simple and minimizes the powder flow, because the powder is discharged from a capillary; thus, flow sensitivity is high compared with other methods. However, where the adhesion forces between particles are too large, bridging will occur in the capillary, thus making the measurement difficult even though the vibration is increased.

To solve the problem of the capillary method and to increase measurement capability, we have developed a new evaluation method using a vibrating tube and a bottom surface. Since the vibration is transferred directly to the particles in the narrow gap between the vibrating tube edge and the flat bottom surface, the particles experience high shear forces to overcome the adhesion and friction forces. As a result, the particles can be discharged through the gap. In the present work, the performance of this system is studied using two factors, i.e. critical vibration acceleration and characteristic mass flow rate, focusing on the effect of the gap distance, the surface roughness of the bottom, and the vibration condition on the powder flowability measurement.

\section{Experiments}

\subsection{Experimental setup}

Fig.1 shows a schematic diagram of the experimental setup. The measurement section consists of a glass tube, a bottom made of metal, and a piezoelectric vibrator. The glass tube, $200 \mathrm{~mm}$ long, $8 \mathrm{~mm}$ in inner diameter and $10 \mathrm{~mm}$ in outer diameter, was held vertically, and the bottom with a diameter of $10 \mathrm{~mm}$ was placed below the tube with a narrow gap. The gap distance, which is the width of the outlet slit for powder discharge, can be varied manually by means of a screw micrometer. The piezoelectric 
vibrator was fixed to the tube at the height of $50 \mathrm{~mm}$ from the end of the tube. In this arrangement, relative movement can occur in the gap due to the horizontal vibration of the tube. The vibration amplitude was measured at the height of $10 \mathrm{~mm}$ from the end of the tube using a laser vibrometer, and controlled by a feedback system (VST-01 Control system, IMP. Co., Ltd.), so as to increase the vibration amplitude at a constant rate of $0.25,0.5,0.75$ or $1 \mu \mathrm{m} / \mathrm{s}$ up to $100 \mu \mathrm{m}$. The vibration acceleration $\alpha$ was calculated by

$$
\alpha=A(2 \pi f)^{2}
$$

where $A$ is the vibration amplitude and $f$ is the frequency. In this system, the frequency was fixed at $300 \mathrm{~Hz}$ to utilize the resonance that can vibrate with large amplitude. A digital balance with a resolution of $0.1 \mathrm{mg}$ and a response time of $1 \mathrm{~s}$ was used to measure the mass of particles discharged. All the data were recorded in the computer at intervals of $4 \mathrm{~s}$.

\subsection{Experimental procedure}

In order to study the state of powder flow at the outlet slit, observations were carried out using a high-speed microscope camera with a resolution of $1 \mu \mathrm{m}$ (Fastcam-Max, Photron Ltd.). The images were recorded at a rate of 4000 frames per second and analyzed by digital image processing.

The amount of powder required for the repeated measurements was about 10-40 g, depending on the particle packing density. A powder sample was filled into the tube through a removable funnel, and a pretest under vibration was carried out to fill it uniformly with powder; then the measurement was repeated 8 times under the same conditions. The height of the powder bed in the tube was more than $160 \mathrm{~mm}$ during 
the measurement. For the evaluation of the flowability, the mean and the standard error of the mean, which is the standard deviation divided by the square root of the number of measurements, were taken into consideration.

The effect of three parameters, i.e. the surface roughness of the bottom, the gap distance, and the increasing rate of the vibration acceleration on the powder flowability measurement was studied. As a standard condition for the measurement, the average surface roughness of $R_{\mathrm{a}}=0.38 \mu \mathrm{m}$, the gap distance of $h=0.4 \mathrm{~mm}$, and the increasing rate of the vibration acceleration of $\mathrm{d} \alpha / \mathrm{d} t=1.8 \mathrm{~m} / \mathrm{s}^{3}$ were adopted. To study the effect of the surface roughness, three bottom surfaces with $R_{\mathrm{a}}=0.38,0.52$ and $2.71 \mu \mathrm{m}$ were prepared. The surface roughness of the tube edge was $R_{\mathrm{a}}=0.46 \mu \mathrm{m}$. Fig. 2 shows the representative profiles of the surface roughness obtained using a laser focus scanning device (LT-8010, Keyence Corp.). For the study on the effect of the gap distance, four distances $(h=0.4,0.6,0.8$, and $1.0 \mathrm{~mm})$ were chosen. As for the study on the effect of the increasing rate of the vibration acceleration, four values $(\mathrm{d} \alpha / \mathrm{d} t=0.9$, $1.8,2.7$, and $3.6 \mathrm{~m} / \mathrm{s}^{3}$ ) were selected.

\subsection{Powder samples}

Five alumina powders with different mass median diameters $\left(D_{\mathrm{p} 50}=2,8,15,31\right.$, and $60 \mu \mathrm{m}$ : JIS Z 8901 Test powder 2) were used. The particles were irregular in shape, the particle density was $4000 \mathrm{~kg} / \mathrm{m}^{3}$, and the purity of alumina was $98 \%$. The powders were dried at $120^{\circ} \mathrm{C}$ for $24 \mathrm{~h}$ and stored in a dessicator at a relative humidity of about $30 \%$. All measurements were carried out at room temperature of $25 \pm 2{ }^{\circ} \mathrm{C}$ and relative humidity of $40 \pm 5 \%$. 


\section{Results and discussions}

\subsection{Observation of powder flow}

Fig.3 illustrates the mechanism of powder flow in this system, which is based on the observation with the high speed microscope camera. For no or low vibration, downward flow in the tube due to gravity is prevented by cohesive arching and the static friction against the vertical wall and the flat bottom surface. The particles in the gap experience horizontal forces due to powder pressure; however, horizontal flow is also prevented by the static friction against the surrounding walls. When the glass tube vibrates horizontally, a small clearance is formed between the vertical wall and the powder bed; thus, the wall friction will be reduced [21, 22] and the powder bed can move downward due to gravity. In the gap, a shear field is generated by the vibration of the tube, where adhesion forces between particles are overcome by forces generated in the shear field. In other words, the vibration causes the particles to lose contact and flow out of the outlet slit by the powder pressure under gravity. Here, it is worth noting that a pulsating flow occurs in the region close to the edge of the vibrating tube. The frequency of the pulsating flow was $300 \mathrm{~Hz}$, which is equal to the frequency of the piezoelectric vibrator. Therefore, the particles in the gap move in response to quick changes in the external forces.

\subsection{Powder flow profile}

Fig. 4 shows the mass of particles discharged as a function of time elapsed. These results were obtained under the condition where the vibration acceleration increased linearly with time for $200 \mathrm{~s}$. The particle discharge begins at a certain time and the mass of particles discharged increases with elapsed time, depending on the mass median 
diameter. The error bar, which is standard error for 8 measurements, is small compared with the variation of the average value; thus, it can be seen that the repeatability is good. The difference in powder flowability caused by increasing mass median diameter is seen in this figure; however, to investigate the flow state in more detail, the relationship between the mass flow rate and the vibration acceleration (hereafter called as 'flowability profile') should be evaluated.

Fig.5 shows the flowability profiles obtained from the results in Fig. 4 . The mass flow rate increases with the vibration acceleration after exceeding a certain critical vibration acceleration, and also increases with increasing mass median diameter. These features indicate that larger particles have higher flowability. The lower graph in this figure shows magnified flowability profiles in the region of low mass flow rate. The difference of the critical vibration acceleration to make particles flow is clearer than that in the upper graph.

The relative positions of the particles do not change even though the system is vibrated at lower amplitude; however, after exceeding the critical vibration acceleration, the relative positions can change and the particles flow. Therefore, the critical vibration acceleration is related to the static friction, and a lower value of the critical vibration acceleration indicates higher flowability.

The procedure to evaluate static and dynamic properties is shown in Fig.6. The state around the critical vibration acceleration may not always be clear; thus, a threshold is needed to evaluate the static property. The mass flow rate of $0.002 \mathrm{~g} / \mathrm{s}$ was chosen as the threshold $w_{\mathrm{c}}$, and the critical vibration acceleration $\alpha_{\mathrm{c}}$ was determined for the corresponding vibration acceleration. On the other hand, to evaluate the dynamic property related to the dynamic friction of particles, a characteristic mass flow rate $w_{\alpha}$ at 
a given vibration acceleration was introduced. A value of $300 \mathrm{~m} / \mathrm{s}^{2}$ was chosen as the vibration acceleration, at which a stable powder flow was observed for all the samples.

\subsection{Effect of surface roughness of bottom}

Fig.7 shows the relationship between the critical vibration acceleration and the mass median diameter of particles as a parameter of the surface roughness of the bottom. As the mass median diameter increases from 2 to $15 \mu \mathrm{m}$, the critical vibration acceleration decreases significantly; however the variation is small in the range from 15 to $60 \mu \mathrm{m}$. These features indicate that the static property in flowability greatly depends on the mass median diameter for fine particles less than $15 \mu \mathrm{m}$. In general, fine particles tend to agglomerate because of adhesiveness; hence, higher vibration acceleration is required to disintegrate the agglomerates and to discharge the particles from the outlet slit. For the surface roughness of $2.71 \mu \mathrm{m}$, the values of the critical vibration acceleration in the range from 15 to $60 \mu \mathrm{m}$ are slightly higher. However, where the surface roughness is less than $1 \mu \mathrm{m}$, the effect of the surface roughness on the critical vibration acceleration is negligible.

Fig. 8 shows the relationship between the characteristic mass flow rate and the mass median diameter of particles as a parameter of the surface roughness of the bottom. The characteristic mass flow rate increases significantly with increasing mass median diameter in the range from 2 to $15 \mu \mathrm{m}$ irrespective of the degree of the surface roughness of the bottom; however, for the particles larger than $15 \mu \mathrm{m}$, the variation of the characteristic mass flow rate is small. In addition, the effect of surface roughness on the characteristic mass flow rate is somewhat large for particles of $60 \mu \mathrm{m}$.

From the results shown in Figs.7 and 8, it is found that the effect of the surface 
roughness of the bottom on the flowability is small for fine particles less than a few tens micrometers, and the static and dynamic properties depend on the mass median diameter. Therefore, the flowability obtained in this system is based on the inherent characteristics of particles.

\subsection{Effect of gap distance}

Fig. 9 shows the relationship between the critical vibration acceleration and the gap distance. For fine particles as small as $8 \mu \mathrm{m}$ or less in mass median diameter, the critical vibration acceleration greatly decreases with increasing gap distance, in particular at larger gap distance $(h>0.6 \mathrm{~mm})$. This feature indicates that fine particles can more easily flow out of the tube by enlarging the gap. In general, fine particles tend to agglomerate and block the passage. For a narrow gap, high vibration is required to disintegrate the agglomerates into small pieces and to flow through the gap; while for a wide gap, high vibration is not needed. Therefore, this evaluation method gives the information of the flowability related to the strength of the agglomerates. When high sensitive measurement is needed to distinguish the small difference between powders with similar flowability, the gap distance should be decreased though high vibration acceleration is required.

Fig.10 shows the relationship between the characteristic mass flow rate and the gap distance. The characteristic mass flow rate increases with increasing gap distance and mass median diameter. These results show that the dynamic property can be properly evaluated in the range of the gap from 0.4 to $1 \mathrm{~mm}$. From the view point of the reduction of the sample amount, a small gap distance is better. 


\subsection{Effect of increasing rate of vibration acceleration}

In this section, the effect of the time required for a measurement on the flowability evaluation was investigated. The measurement time was varied in the range from 100 to $400 \mathrm{~s}$, and thus the increasing rate of the vibration acceleration was varied from 3.6 to $0.9 \mathrm{~m} / \mathrm{s}^{3}$. Fig. 11 shows the relationship between the critical vibration acceleration and the increasing rate of the vibration acceleration. No significant changes were found in this variable; thus, the particles in the gap begin to flow in response to changes in the vibration acceleration. Such a high responsive particle behavior is also confirmed by the observation using a high speed microscope camera as mentioned in Section 3.1.

Fig.12 shows the relationship between the characteristic mass flow rate and the increasing rate of the vibration acceleration. Similar to Fig. 11, there are no significant changes in this variable. Therefore, short measurement time is better for the reduction of the sample amount as well as the improvement of the measurement efficiency. However, if the increasing rate of the vibration acceleration is too high, the measurement accuracy will be reduced. Here, we will mention the measurement accuracy for the critical vibration acceleration. The relative error of the critical vibration acceleration $E_{\mathrm{r}}$ can be expressed as a function of the increasing rate of the vibration acceleration $\mathrm{d} \alpha / \mathrm{d} t$, the time intervals of data logging $\delta t$, and the critical vibration acceleration $\alpha_{\mathrm{c}}$.

$$
E_{\mathrm{r}}=\frac{\mathrm{d} \alpha}{\mathrm{d} t} \frac{\delta t}{\alpha_{\mathrm{c}}}
$$

Therefore, the relative error can be reduced by decreasing the time interval. Of course, $\mathrm{d} \alpha / \mathrm{d} t, \alpha_{\mathrm{c}}$ and response time as well as $\delta t$ should be taken into account for the accuracy and the improvement of the measurement efficiency. 


\section{Summary and conclusions}

A new method for evaluating powder flowability, named vibration shear tube method has been developed. The measurement section was made up of a glass tube with a piezoelectric vibrator and a bottom. The frequency of the applied vibration was constant at $300 \mathrm{~Hz}$, and the vibration amplitude was increased with time at a constant rate. The samples used for the experiments were alumina particles with $2-60 \mu \mathrm{m}$ in mass median diameters. The mass of particles discharged through the narrow gap between the vibrating tube edge and the flat bottom surface was measured at constant time intervals. Experimentally obtained flowability profiles, i.e. the relationship between the mass flow rate and the vibration acceleration were analyzed. The results obtained are summarized as follows:

1. During vibration, a shear field is formed in the gap, and a pulsating flow occurs in the particle layer close to the edge of the tube. The frequency of the pulsating flow is $300 \mathrm{~Hz}$, which is equal to the frequency of the piezoelectric vibrator. Therefore, the particles in the gap can move in response to quick changes in the external forces.

2. The critical vibration acceleration to make particles flow and the characteristic mass flow rate at a given vibration acceleration can be used to evaluate the static and dynamic properties in powder flowability.

3. The effect of surface roughness of the bottom on the flowability is small for fine particles less than a few tens micrometers, and the flowability depends on the mass median diameter.

4. As the gap distance decreases, the measurement sensitivity of the static property of fine particles increases. In this condition, high vibration is required to disintegrate 
the agglomerates into small pieces and to flow through the gap. Therefore, this evaluation method gives the flowability related to the disintegration of the agglomerates.

5. The measurement time can be reduced by enlarging the increasing rate of the vibration acceleration. A short measurement time leads to the reduction of the sample amount as well as the improvement of the measurement efficiency.

6. The relative error of the measurement is proportional to the increasing rate of the vibration acceleration and/or the time interval of data logging, and inversely proportional to the critical vibration acceleration.

\section{Acknowledgments}

The authors acknowledge the financial support from the Information Center of Particle Technology, Japan. This research was also supported by a Grant no. S0901039 from MEXT, Japan and the program to promote a career path for research personnel of academia and accelerate technology transfer, JST.

\section{References}

[1] J. Schwedes, Review on testers for measuring flow properties of bulk solids, Granular Matter 5 (2003) 1-43.

[2] J.K. Prescott, R.A. Barnum, On powder flowability, Pharmaceutical Technology 24 (2000) 60-84.

[3] K. Ishii, M. Suzuki, T. Yamamoto, Y. Kihara, Y. Kato, T. Kurita, K. Yoshimoto, M. Yasuda, S. Matsusaka, Flowability measurement of coarse particles using vibrating tube method, Journal of Chemical Engineering of Japan 42 (2009) 
$319-324$.

[4] W. Yu, K. Muteki, L. Zhang, G. Kim, Prediction of bulk powder flow performance using comprehensive particle size and particle shape distributions, Journal of Pharmaceutical Sciences 100 (2011) 284-293.

[5] J.J. Fitzpatrick, M. Hodnett, M. Twomey, P.S.M. Cerqueira, J. O'Flynn, Y.H. Roos, Glass transition and the flowability and caking of powders containing amorphous lactose, Powder Technology 178 (2007) 119-128.

[6] K.C. Pingali, K. Saranteas, R. Foroughi, F.J. Muzzio, Practical methods for improving flow properties of active pharmaceutical ingredients, Drug Development and Industrial Pharmacy 35 (2009) 1460-1469.

[7] Q. Zhou, B. Armstrong, I. Larson, P.J. Stewart, D.A.V. Morton, Improving powder flow properties of a cohesive lactose monohydrate powder by intensive mechanical dry, Journal of Pharmaceutical Science 99 (2010) 969-981.

[8] L.J. Jallo, M. Schoenitz, E.L. Dreizin, R.N. Dave, C.E. Johnson, The effect of surface modification of aluminum powder on its flowability, combustion and reactivity, Powder Technology 204 (2010) 63-70.

[9] Y. Jiang, S. Matsusaka, H. Masuda, Y. Qian, Development of measurement system for powder flowability based on vibrating capillary method, Powder Technology 188 (2009) 242-247.

[10] M. Krantz, H. Zhang, J. Zhu, Characterization of powder flow: static and dynamic testing, Powder Technology 194 (2009) 239-245.

[11] R.L. Carr, Evaluating flow properties of solids, Chemical Engineering, January 18 (1965) 163-168.

[12] A. W. Jenike, Gravity flow of bulk solids, Bulletin No. 108, Utah Engineering 
Experiment Station, Univ. of Utah, 1961.

[13] ISO4490 (2008) Metallic powders, Determination of flow time by means of a calibrated funnel (Hall flowmeter).

[14] ASTM D6128-06 (2006) Standard test method for shear testing of bulk solids using the Jenike shear cell.

[15] D. Schulze, Powders and Bulk Solids: Behavior, Characterization, Storage and Flow, Springer, New York, 2008.

[16] A. Hassanpour, M. Ghadiri, Characterisation of Flowability of Loosely Compacted Cohesive Powders by Indentation, Particle \& Particle Systems Characterization 24 (2007) 117-123.

[17] S.N. Bhattachar, D.B. Hedden, A.M. Olsofsky, X. Qu, W.-Y. Hsieh, K.G. Canter, Evaluation of the vibratory feeder method for assessment of powder flow properties, International Journal of Pharmaceutics 269 (2004) 385-392.

[18] F. Lavoie, L. Cartilier, R. Thibert, New methods characterizing avalanche behavior to determine powder flow, Pharmaceutical Research 19 (2002) 887-893.

[19] R. Freeman, Measuring the flow properties of consolidated, conditioned and aerated powders - A comparative study using a powder rheometer and a rotational shear cell, Powder Technology 174 (2007) 25-33.

[20] Y. Jiang, S. Matsusaka, H. Masuda, T. Yokoyama, Evaluation of flowability of composite particles and powder mixtures by a vibrating capillary method, Journal of Chemical Engineering of Japan 39 (2006) 14-21.

[21] S. Matsusaka, M. Urakawa, H. Masuda, Micro-feeding of fine powders using a capillary tube with ultrasonic vibration, Advanced Powder Technology 6 
(1995) 283-293.

[22] S. Matsusaka, K. Yamamoto, H. Masuda, Micro-feeding of a fine powder using a vibrating capillary tube, Advanced Powder Technology 7 (1996) 141-151. 


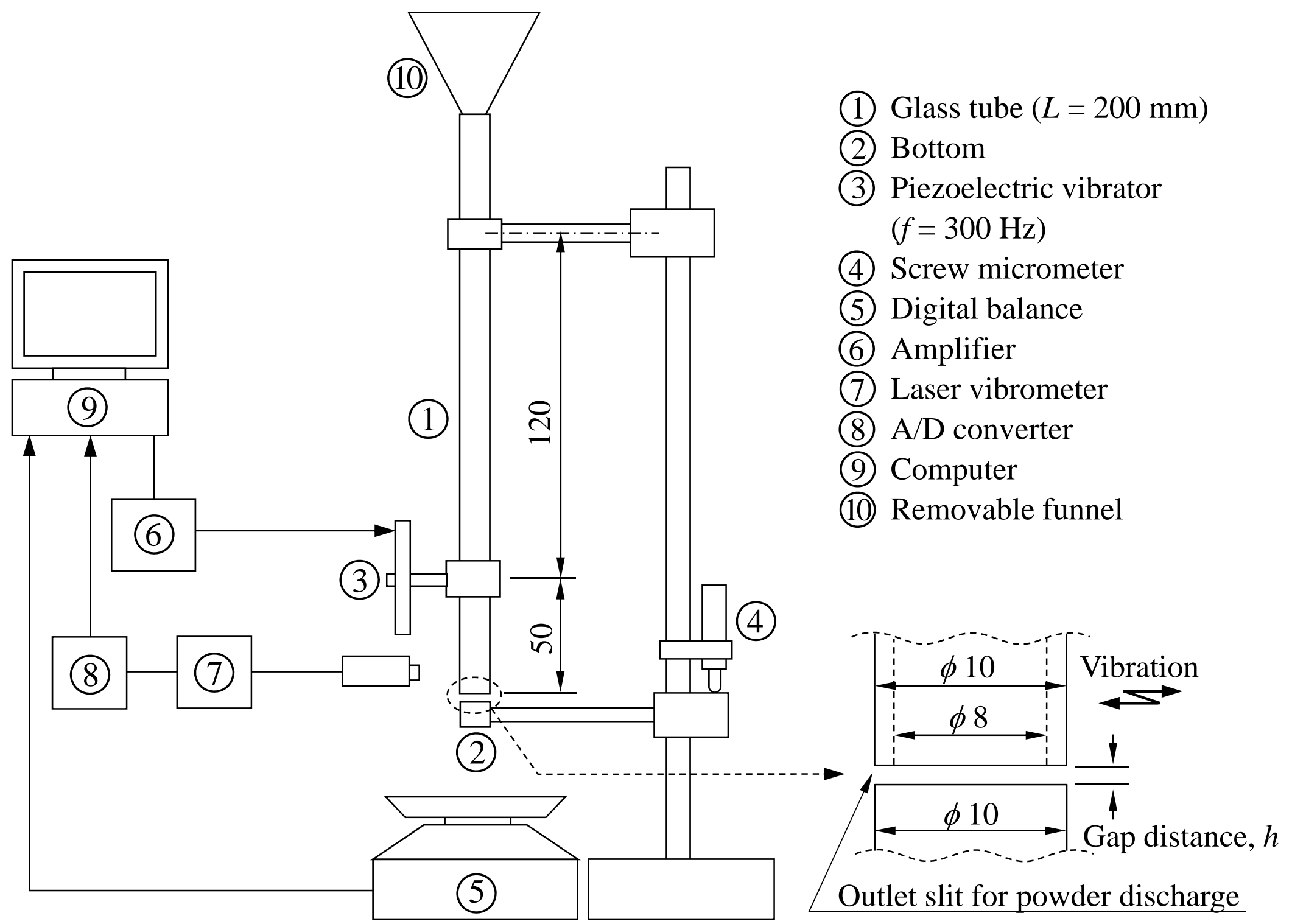

Fig. 1. Schematic diagram of experimental setup. 


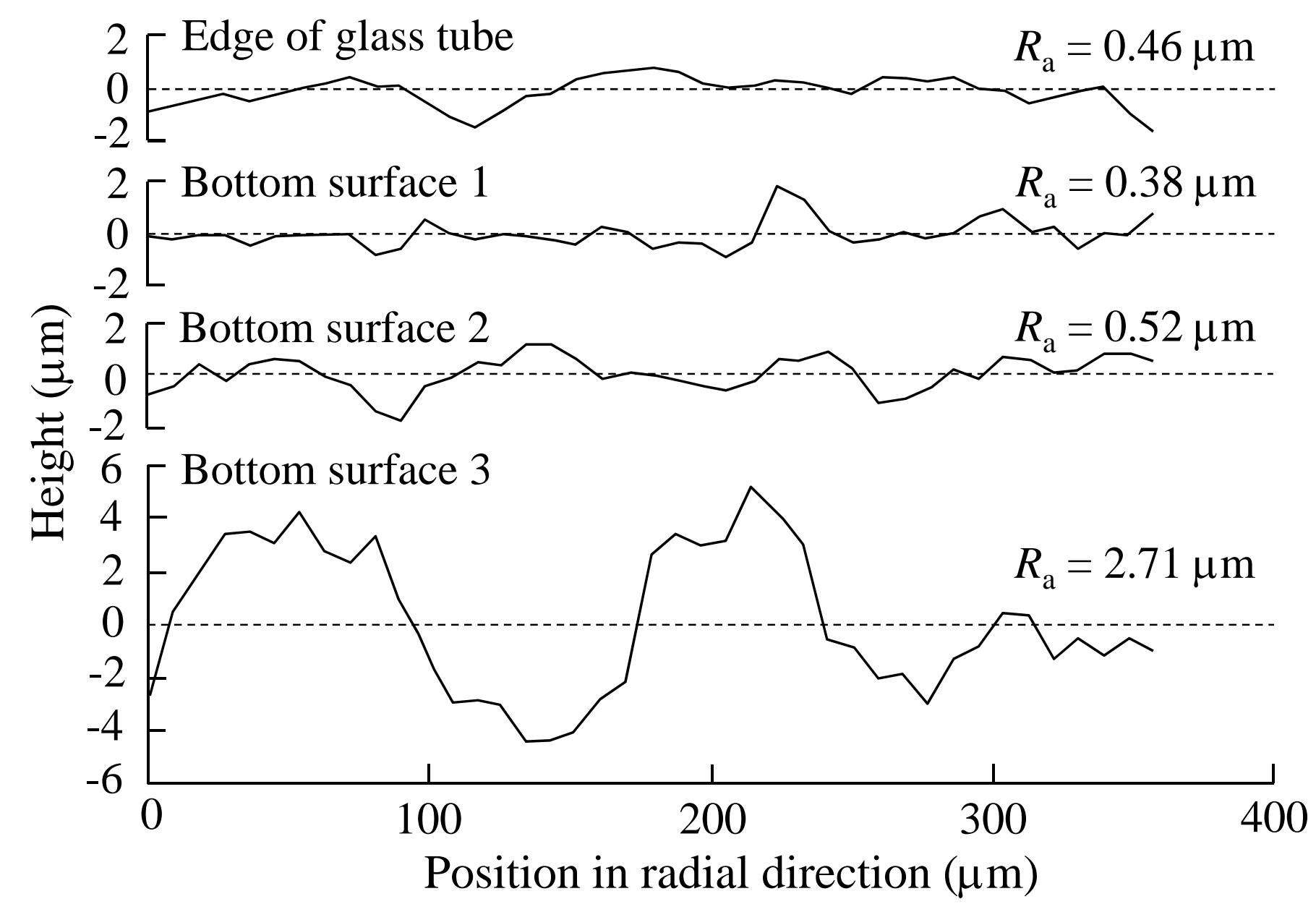

Fig. 2. Profiles of surface roughness of tube edge and bottom surfaces. 


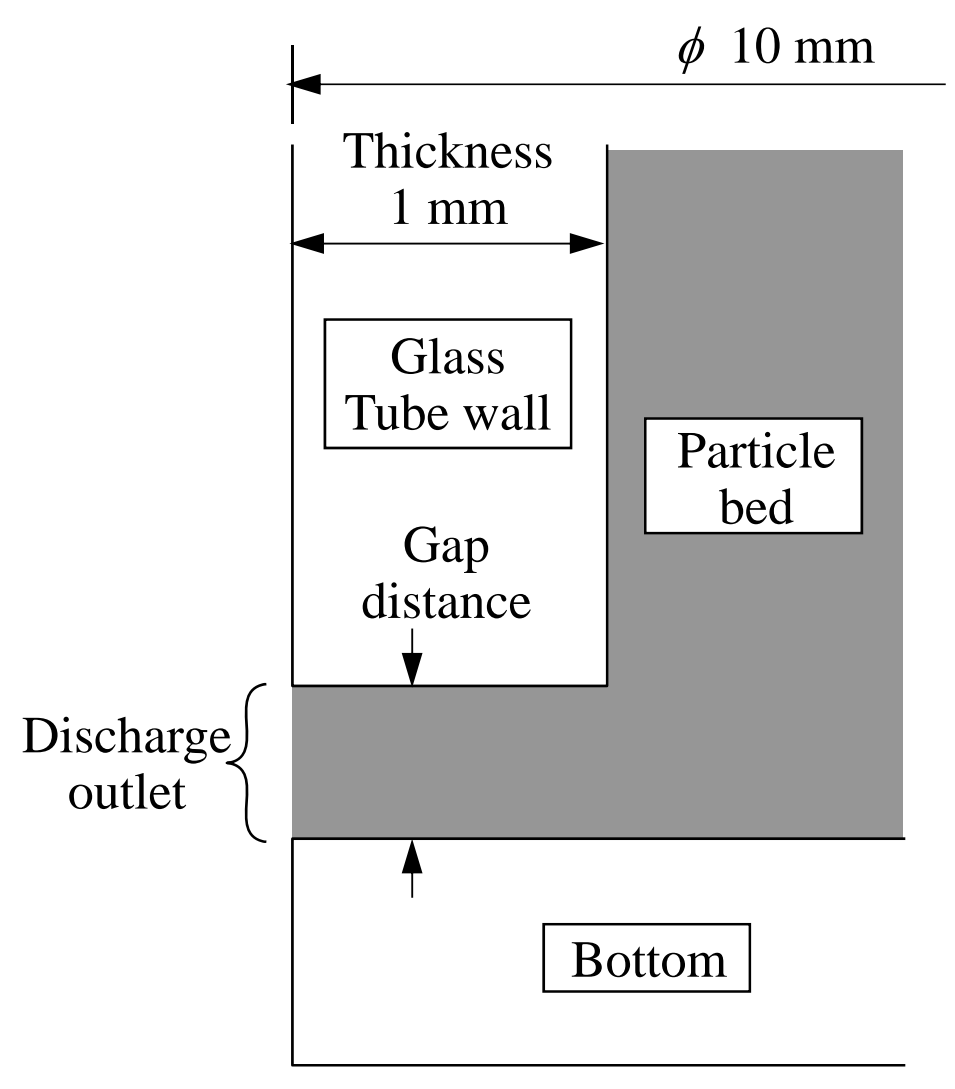

a) No vibration

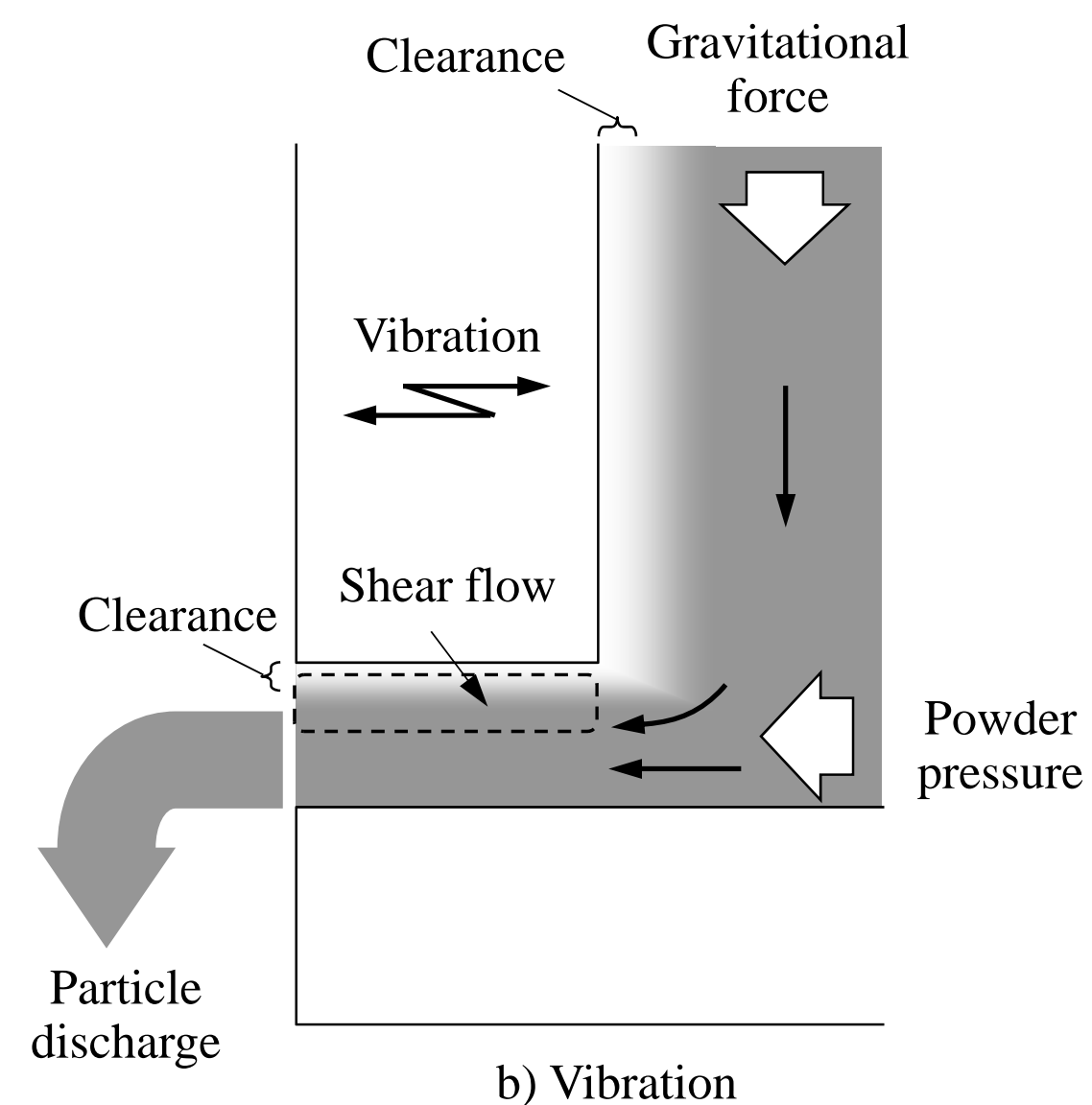

b) Vibration

Fig. 3. Mechanism of powder flow in this system. 


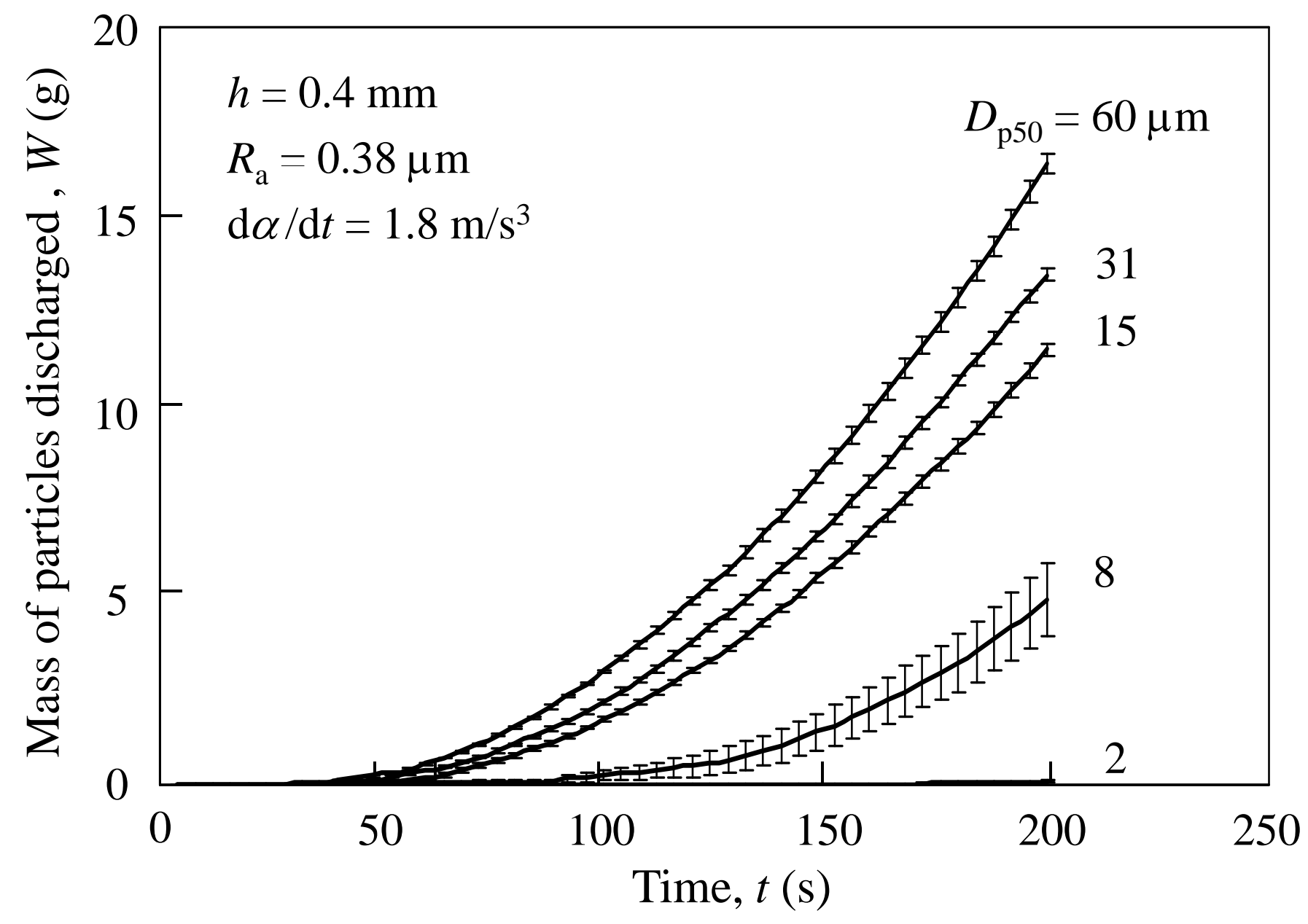

Fig. 4. Mass of particles discharged as a function of time elapsed. 


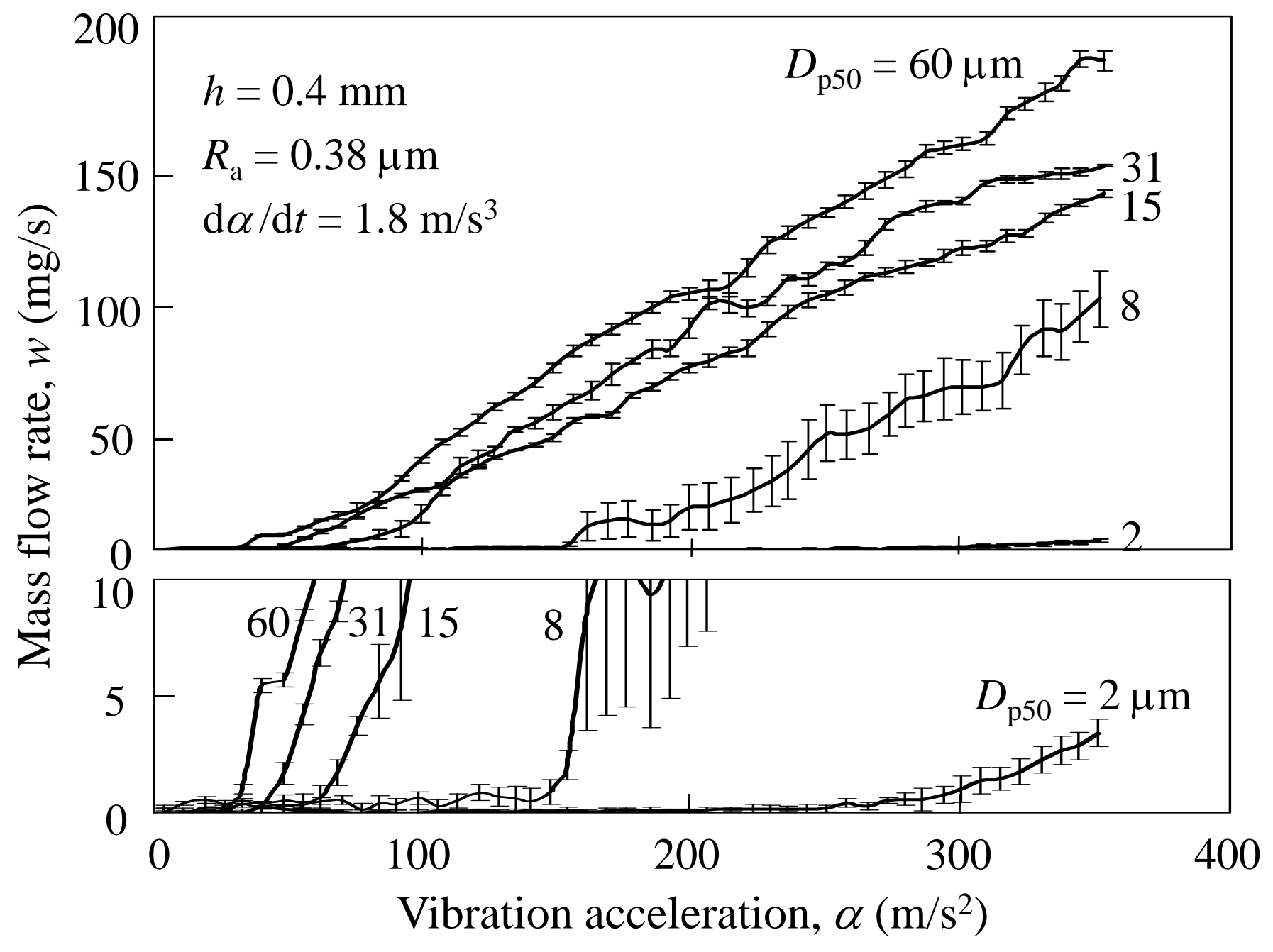

Fig. 5. Powder flow profiles i.e., variation of mass flow rate as a function of vibration acceleration. Lower graph is the magnified profiles. 


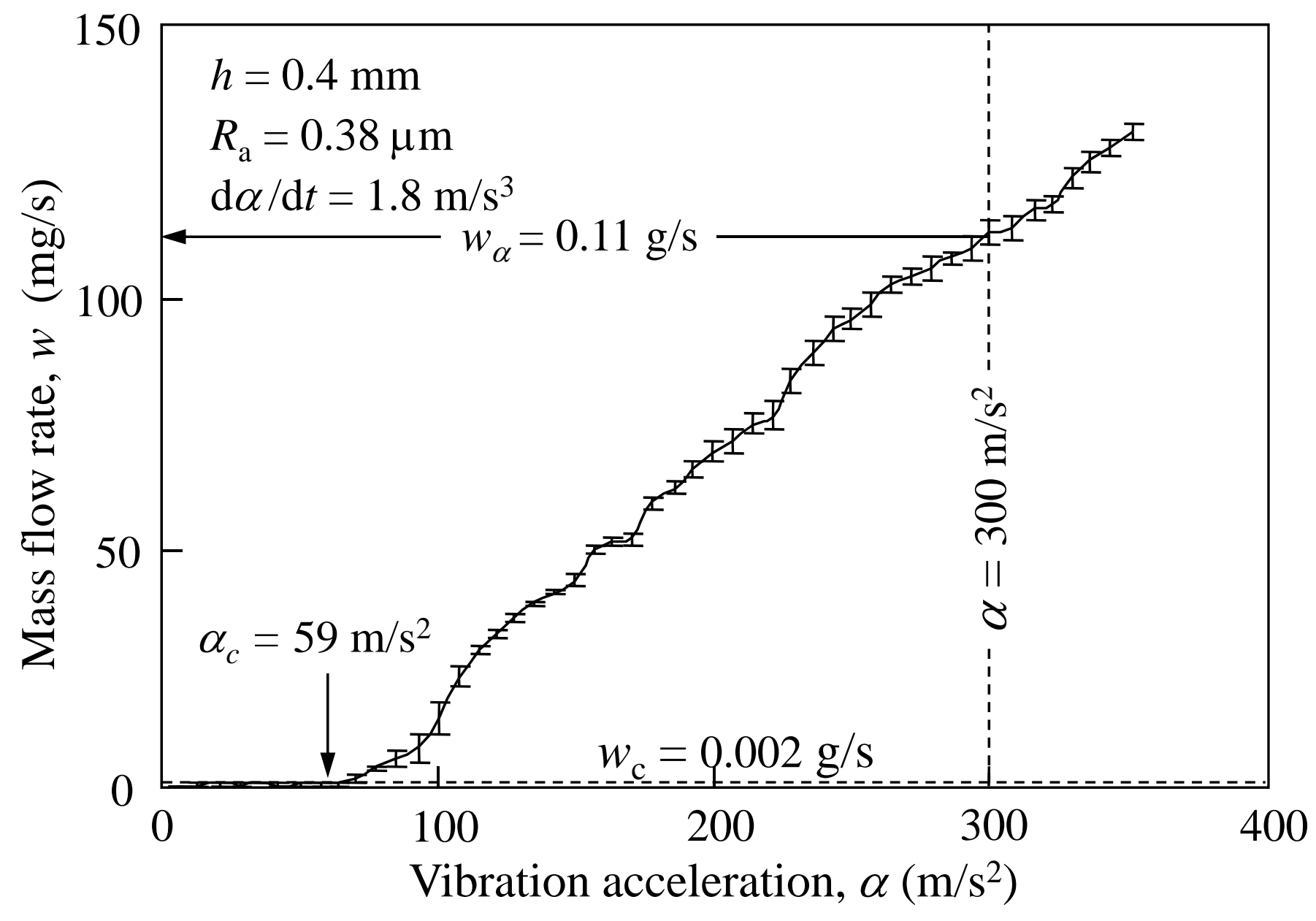

Fig. 6. An example to determine critical vibration acceleration $\alpha_{\mathrm{c}}$ and characteristic mass flow rate $w_{\alpha}$ (flowability profile for $D_{\mathrm{p} 50}=15 \mu \mathrm{m}$ ). 


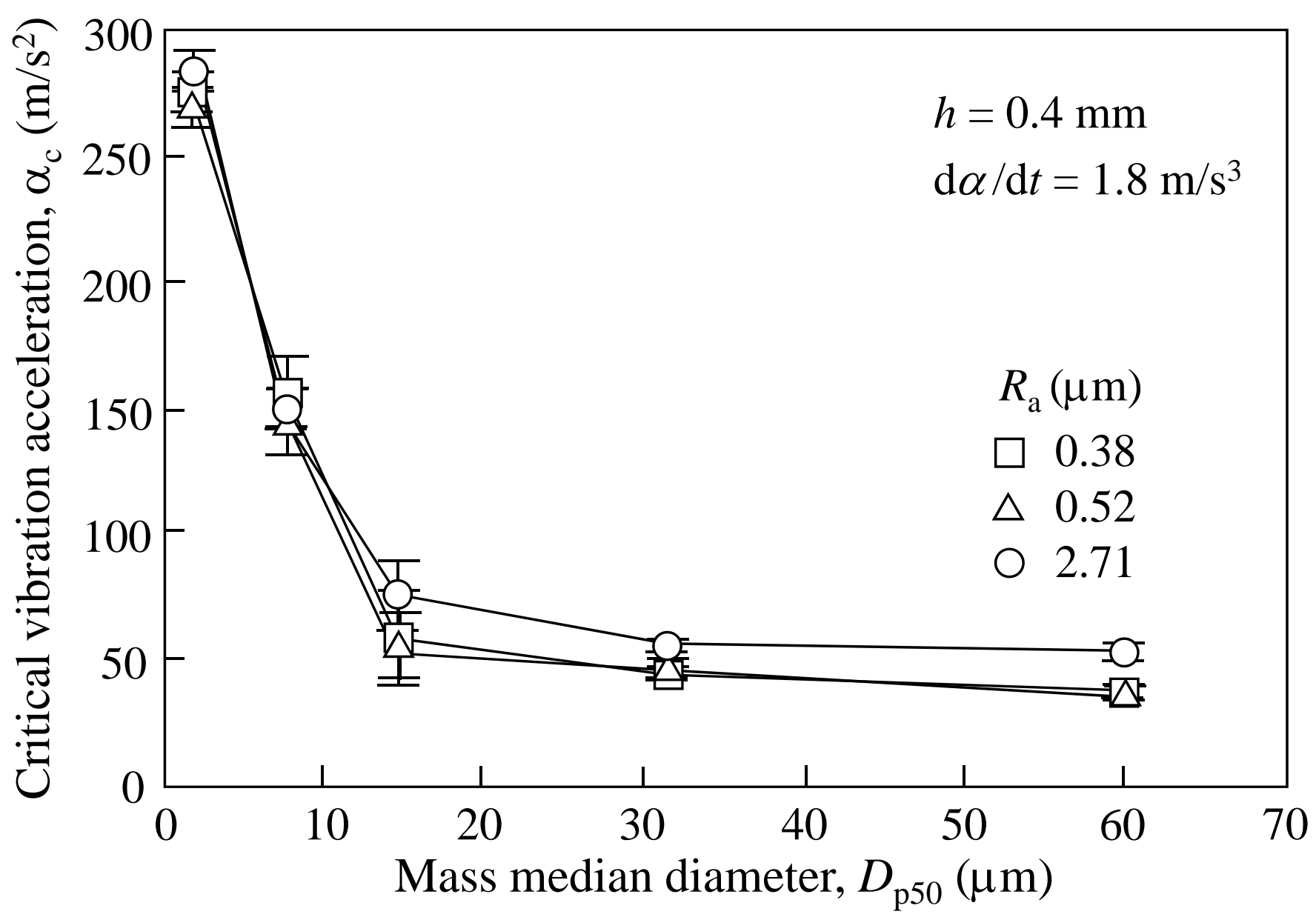

Fig.7. Relationship between critical vibration acceleration and mass median diameter of particles as a function of surface roughness of bottom. 


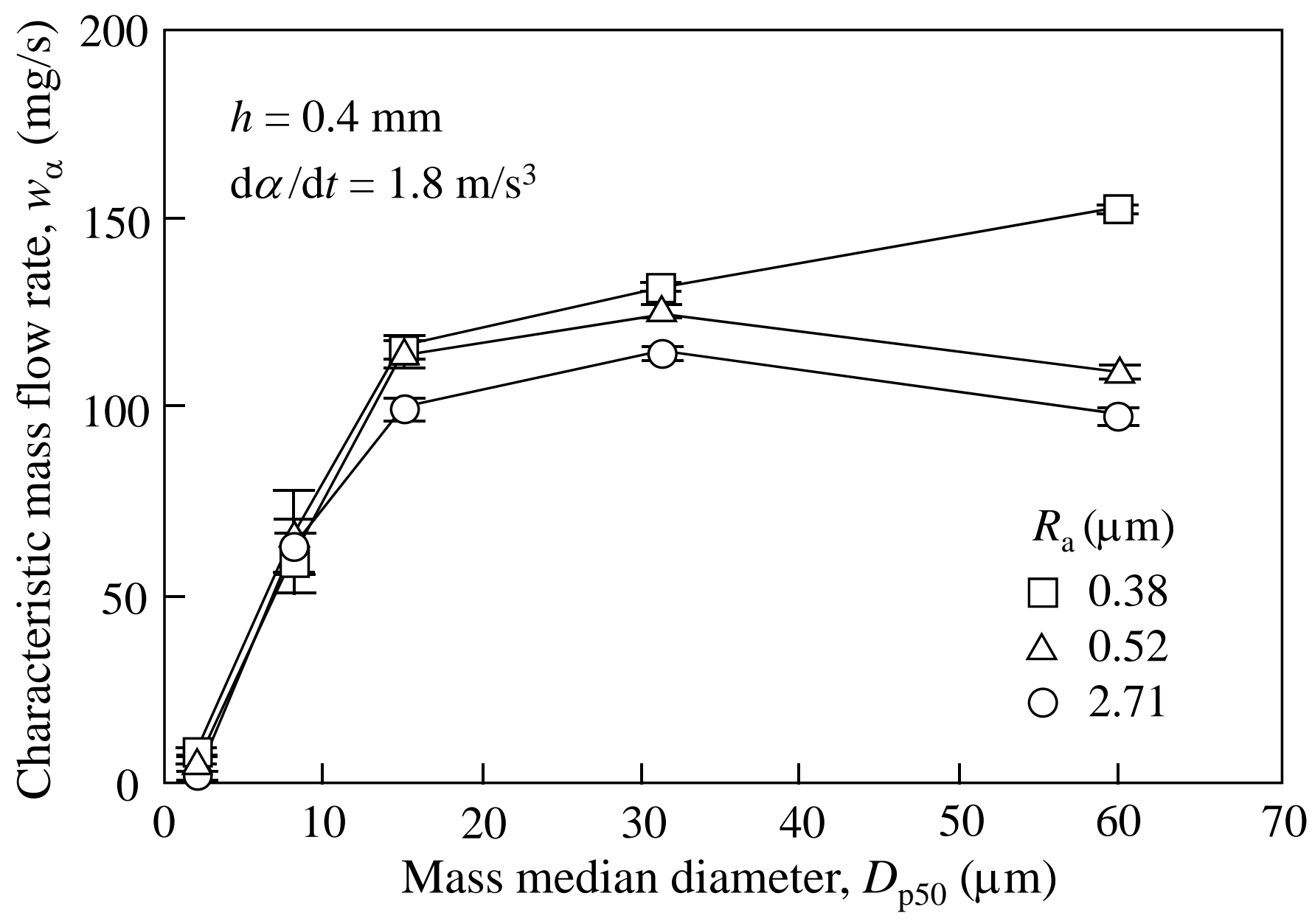

Fig.8. Relationship between characteristic mass flow rate and mass median diameter of particles as a function of surface roughness of bottom. 


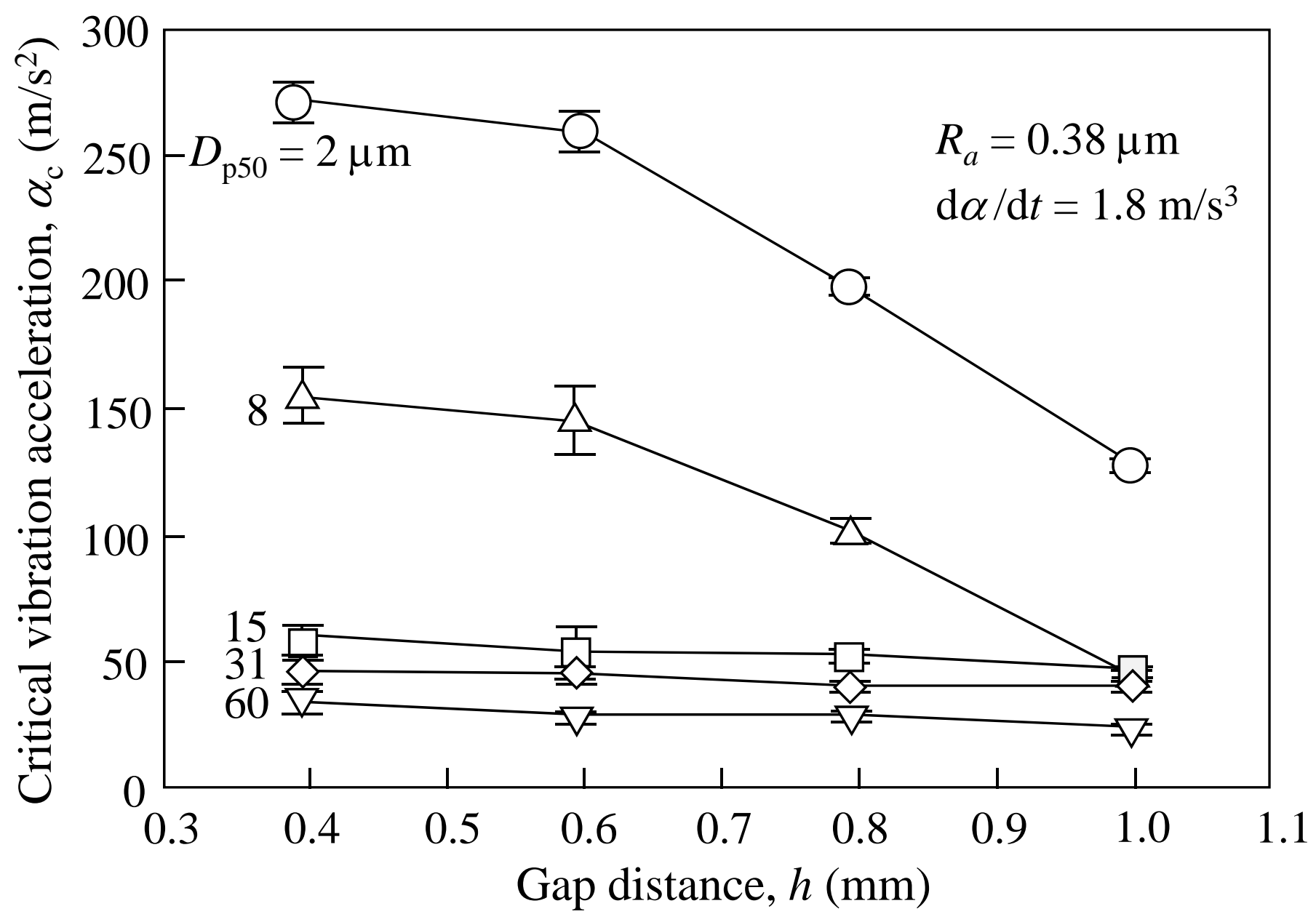

Fig.9. Effect of gap distance on critical vibration acceleration. 


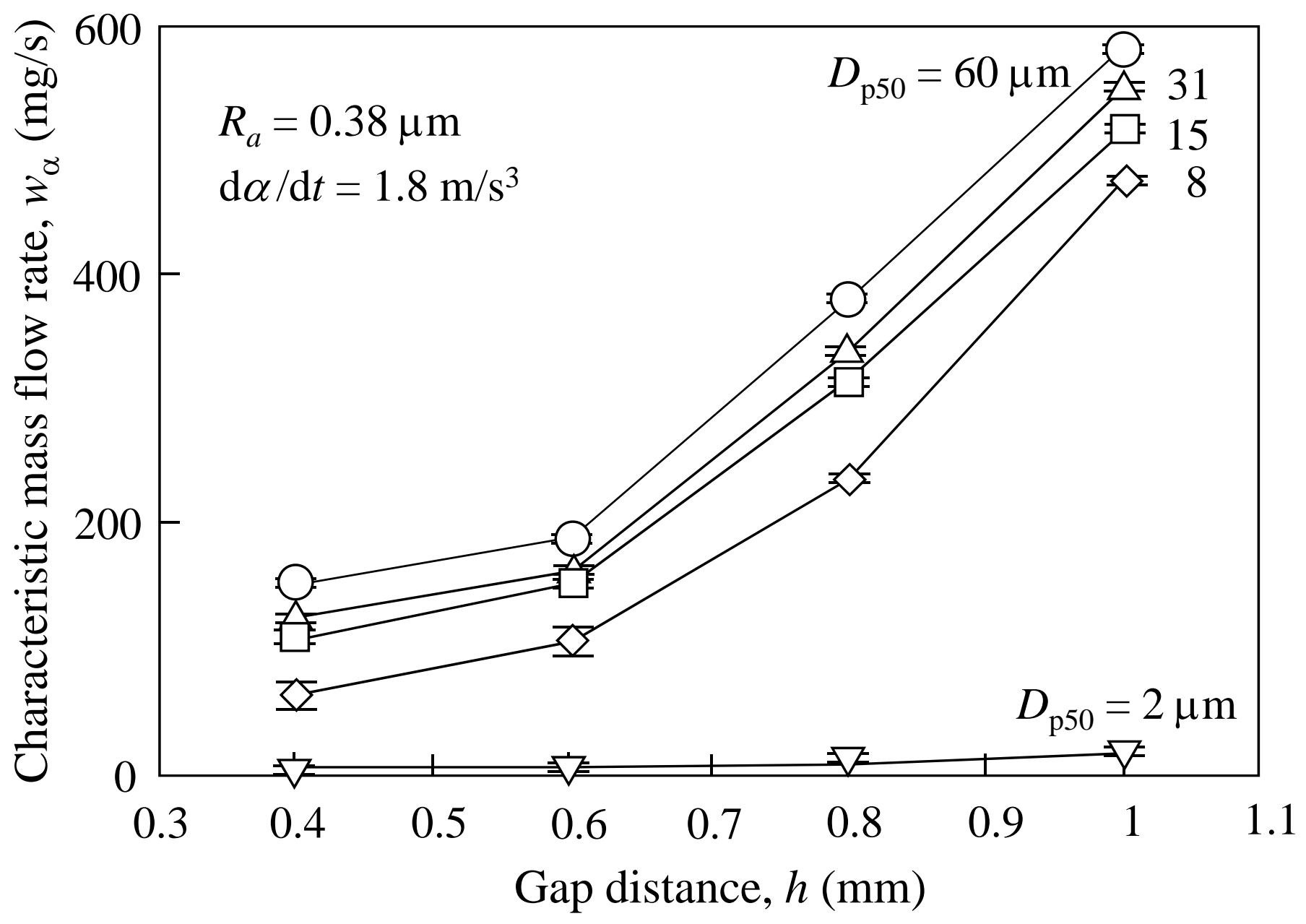

Fig.10. Effect of gap distance on characteristic mass flow rate. 


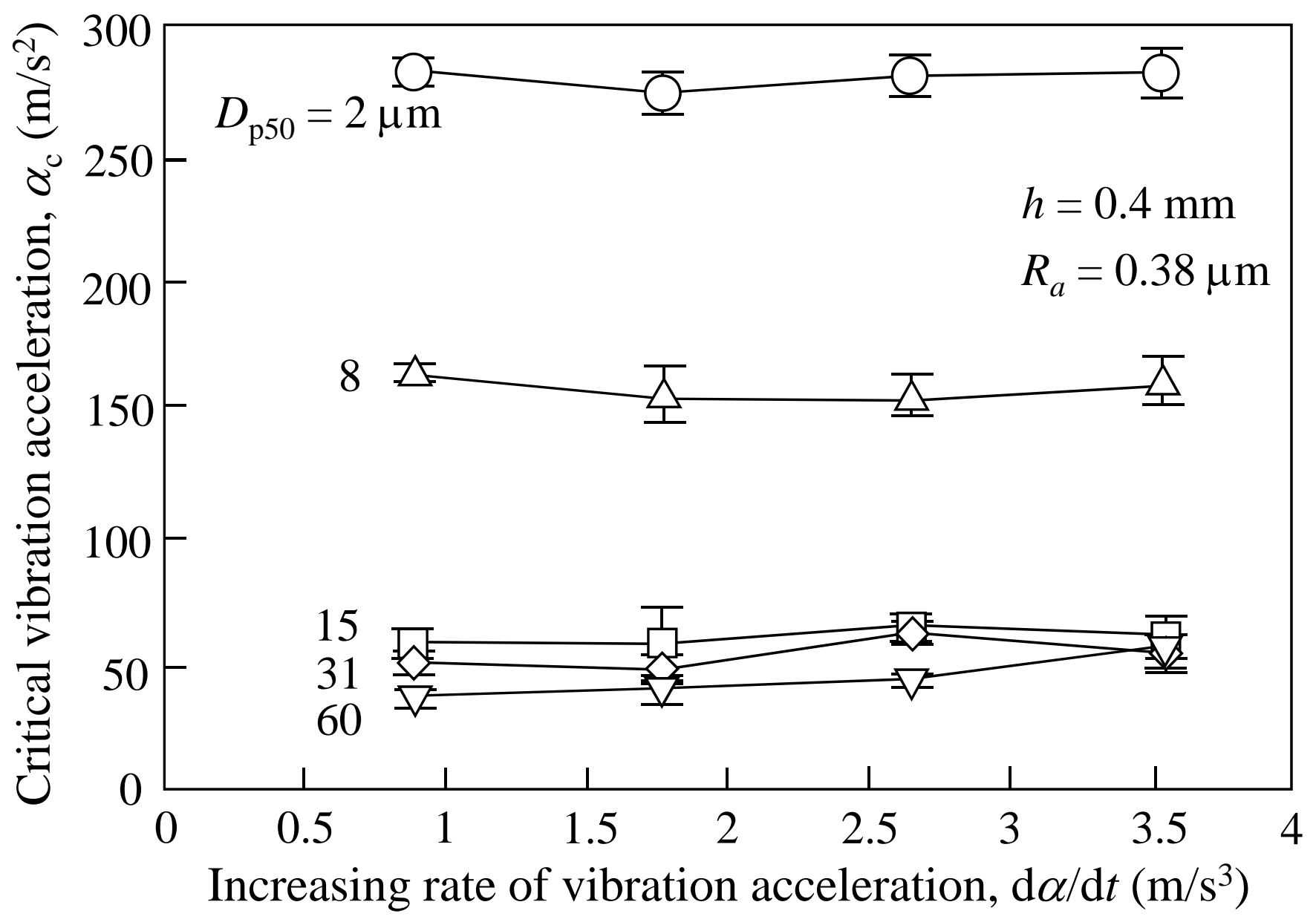

Fig.11. Effect of increasing rate of vibration acceleration on critical vibration acceleration. 


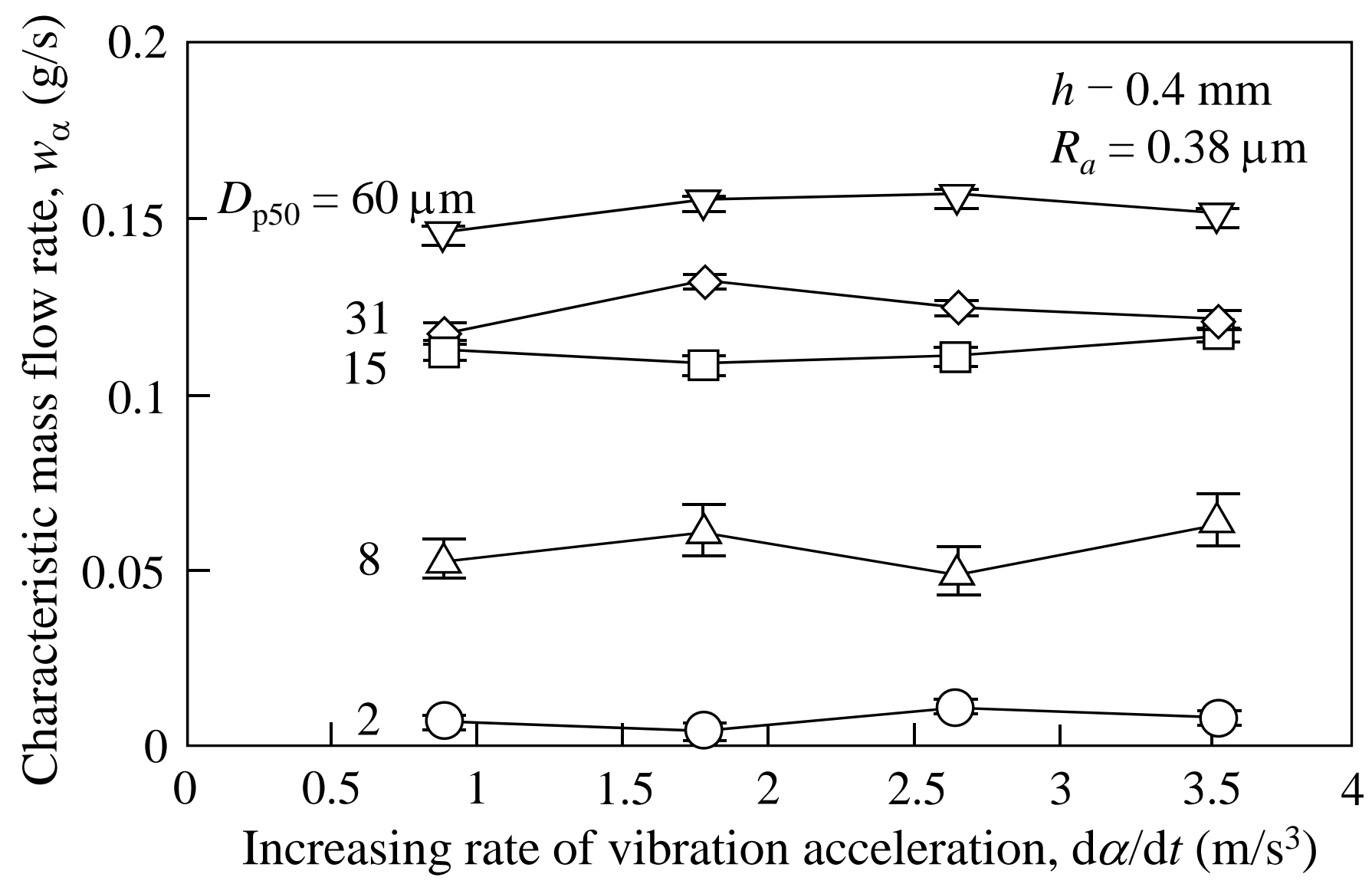

Fig.12. Effect of increasing rate of vibration acceleration on characteristic mass flow rate. 